\title{
S1 Table. Glossary of terms and definitions
}

Table 1. Glossary of terms and definitions.

\begin{tabular}{|l|l|}
\hline Term & Definition \\
\hline Electrophysiology & Studies that record and analyze far-field (gross) potentials, e.g., electroencephalography \\
\hline Neurophysiology & Studies that record and analyze spike-train data from neurons, e.g., AN fiber spike trains \\
\hline Stationarity & $\begin{array}{l}\text { A signal is stationary when the signal parameters do not change over time. For example, a } \\
\text { stochastic signal like white Gaussian noise is stationary if the amplitude probability density } \\
\text { function is constant across time. Similarly, a deterministic pure tone can be considered an } \\
\text { example of a stationary sinusoidal process with a particular amplitude, frequency, and initial } \\
\text { phase. }\end{array}$ \\
\hline Second-order stationarity & $\begin{array}{l}\text { A stochastic signal is second-order stationary if its mean and autocorrelation function do } \\
\text { not change over time. Second-order stationarity is also referred to as wide-sense stationarity. }\end{array}$ \\
\hline Linearity & $\begin{array}{l}\text { A system is linear if it obeys the rules of superposition. For example, consider a system for } \\
\text { which inputs } x_{1} \text { and } x_{2} \text { evoke responses } y_{1} \text { and } y_{2}, \text { respectively. Then, the system is linear } \\
\text { if the response to input } a x_{1}+b x_{2} \text { is } a y_{1}+b y_{2} \text {. An auditory corollary of linearity is that a } \\
\text { linear system }(\text { e.g., the ear canal) processes sound in the same way at soft and loud sound } \\
\text { levels, which means that for every dB increase in the input, the output is increased by the } \\
\text { same dB. }\end{array}$ \\
\hline Time invariance & $\begin{array}{l}\text { A system is time invariant if its parameters (e.g., gain at all frequencies) do not change over } \\
\text { time }\end{array}$ \\
\hline Periodic signal & A perfectly repeating signal, e.g., a tone, or a synthetic vowel with constant pitch \\
\hline Aperiodic signal & A signal that does not repeat, e.g., white Gaussian noise \\
\hline Polarity-tolerant response & Response component that does not depend on stimulus polarity, e.g., the onset response \\
\hline Polarity-sensitive response & $\begin{array}{l}\text { Response component that depends on stimulus polarity, e.g., phase-locked spike trains in } \\
\text { response to a low-frequency tone }\end{array}$ \\
\hline Even sequence & $x[n]$ is even if $x[n]=x[-n]$ \\
\hline Odd sequence & $x[n]$ is odd if $x[n]=-x[-n]$ \\
\hline
\end{tabular}

List of terms with definitions that are frequently used in the present report. 